\title{
Article
}

\section{Psychosocial aesthetics and the art of lived experience}

Bennett, J, Froggett, Lynn and Muller, L

Available at http://clok.uclan.ac.uk/28333/

Bennett, J, Froggett, Lynn ORCID: 0000-0001-8406-6231 and Muller, L (2019) Psychosocial aesthetics and the art of lived experience. Journal of Psychosocial Studies, 12 (1-2). pp. 185-201.

It is advisable to refer to the publisher's version if you intend to cite from the work. http://dx.doi.org/10.1332/147867319X15608718111023

For more information about UCLan's research in this area go to http://www.uclan.ac.uk/researchgroups/ and search for < name of research Group>.

For information about Research generally at UCLan please go to http://www.uclan.ac.uk/research/

All outputs in CLoK are protected by Intellectual Property Rights law, including Copyright law. Copyright, IPR and Moral Rights for the works on this site are retained by the individual authors and/or other copyright owners. Terms and conditions for use of this material are defined in the policies page.

\section{CLoK}

Central Lancashire online Knowledge www.clok.uclan.ac.uk

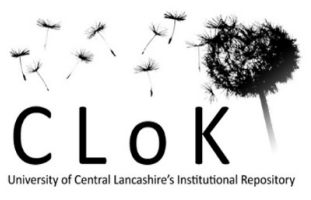




\title{
Psychosocial aesthetics and the art of lived experience
}

\author{
Jill Bennett. Felt Experience \& Empathy Lab [fEEL], University of New South Wales, \\ Sydney, Australia \\ Lynn Froggett. Institute for Citizenship, Society and Change, Psychosocial Research Unit, \\ University of Central Lancashire, Preston, UK \\ Lizzie Muller. Faculty of Art \& Design, University of New South Wales, Sydney, Australia
}

\begin{abstract}
This paper identifies the distinctive nature of arts-based psychosocial enquiry and practice in a public mental health context, focusing on two projects delivered as part of The Big Anxiety festival (Sydney, 2017): Awkward Conversations, in which one-to-one conversations about anxiety and mental health were offered in experimental aesthetic formats, and Parragirls, Past Present, a reparative project, culminating in an immersive film production that explores the enduring effects of institutional abuse and trauma and creates the conditions for symbolic elaboration. Bringing an arts-based enquiry into lived experience into dialogue with psychosocial theory, it examines the transformative potential of aesthetic transactions and facilitating environments, specifically with regard to understanding the imbrication of lived experience and social settings.
\end{abstract}

Keywords aesthetics, psychosocial, affordances, facilitating environment, lived experience

This paper identifies the distinctive nature of arts-based psychosocial research and practice in a public mental health context by focusing on two projects delivered as part of The Big Anxiety festival in Sydney, 2017-Awkward Conversations and Parragirls, Past Present-works that the authors were engaged in both producing and evaluating. If the goal of psychosocial research and practice is to overcome the abstraction of psychology from lived experience (and vice versa), we argue that arts-based methods offer both a potent means of understanding psychosocial processes and of evolving strategies for change. By 'arts-based, psychosocial' we mean arts projects that work from and with lived experience, examining the subjective aspects of that experience in dynamic relation to social, material and institutional settings. It is specifically the capacity to activate and transform a container-contained relationship (Bion, 1970) that defines this as a psychosocial inquiry. However, given this grounding in lived experience, arts-based psychosocial practice is not exclusively or directly derived from existing theory. As a bottom up, generative, endeavour it makes a contribution to knowledge in the field in a distinctively practical form that can be refined and understood through dialogue with psychosocial theory (in our wider practice we have evolved a protocol for formative evaluation; Muller et al, 2018; Bennett et al, 2019; Bartlett \& Muller, 2017).

Our approach as arts-based psychosocial researchers is grounded in the notion of aesthetics as aesthesis (sense-based experience) which has been developed in a body of work spanning philosophy, art theory and psychoanalytic theory. Such work emphasises the aesthetic as a sensori-affective realm of communication which is partly unavailable to conscious awareness or verbal articulation (Bennett, 2005, 2012), and where trauma, pain or distress may manifest in embodied ways as the 'unthought known' (Bollas, 1987) or 'implicit' felt knowledge (Gendlin, 2009). This severs (or at least loosens) the association of aesthetics with judgements 
of taste and beauty - and its exclusive identification with art — and illuminates the aesthetics of everyday sensory experience and what Bollas regards as an aesthetic intelligence at play in all our interactions with others and with the material world (Bollas, 1987, 1992, Bennett \& Froggett, 2019). Everyday aesthetic transactions are the substance of art projects investigating lived experience. Here we aim to show how practice yields a form of enquiry into the aesthetics of lived experience that has potential to make a specific contribution to mental health and wellbeing.

The projects we discuss, offer a terrain on which to investigate - and navigate - the processes and effects of symbolic elaboration and specifically of presentational symbolisation, which Suzanne Langer describes as a process of finding form for feeling, characteristic of art and music (Langer 1942, 1953). Kenneth Wright (2009) points out that the notion of a presentational symbol implies a container-contained structure which 'shows forth' rather than denotes that which it contains: "such a symbol evokes and resonates with the experience stored within it, and from this perspective the container-contained is a living structure consisting of inter-communicating elements" (p.116). In this regard we are interested not only in how the arts accommodate and give expression to the vitality of lived experience but in how there might be a 'carrying forward' of this experience through aesthetic/art practice. This enables us to develop art projects that make a practical contribution to mental health and wellbeing, though for reasons outlined throughout, we understand this contribution to reside in cultural practice rather than a health domain.

As practice-based researchers (Bennett is Director of The Big Anxiety festival, responsible for the design of programs; Froggett and Muller have been engaged in its formative evaluation) we investigate this 'living structure of inter-communicating elements' not as a given but in terms of a field of affordances (Gibson, 1979). Following Gibson, we understand affordances as the possibilities for action and experience that exist in the relationships between the participants and the environments designed and created within these projects. Designing with affordances in mind shifts focus from the idea of shaping or crafting 'an experience' to creating the potential for a repertoire of active engagements. If affordances are perceived as opportunities for action, they are also felt. The concept of the affordance is derived from valence (Gibson, p.138), referring to the emotional value associated with a stimulus, which in turn may be linked to power relations. These affordances, which pertain to relational and sensory interactions, are, of course, a mixture of intentional, accidental and emergent as the creative process proceeds through cycles of action, evaluation and adjustment in situ (Muller, 2015). As Winnicott pointed out "creativity can be destroyed by too great insistence that in acting one must know beforehand what one is doing" (Winnicott [1951] 2000). We discuss below, the practice of working with affordances to create generative and containing settings.

These settings, which may also be understood as 'facilitating environments' (Winnicott, 1965) offer the opportunity for an expanded range of interactions and therefore a potentially enriched lived experience. 'Containment' is envisaged as a guiding curatorial principle in presenting art relating to mental health (Bartlett and Muller, 2017) and the facilitating environment that enables it emerges through a practice-based process of development and testing on the ground.

Our first example is a public engagement program - Awkward Conversations - in which affordances were crafted to create the potential for exchanges which might help participants to articulate and to process objects of hitherto inexpressible anxiety, reaching 'non-help-seekers' and the wider public. Our second example is a reparative project that engaged participants in 
exploring the enduring effects of institutional abuse in which affordances were (historically) systematically diminished and designed to oppress. It culminated in an immersive 3D filmParragirls Past, Present. The goal was to promote conversation between survivors that not only expressed hard-to-articulate, traumatic experience but located this in the environment, bringing to visibility the emotional valences of interpersonal communications in the present, and the effects of micro-interactions in social and institutional settings.

\section{The Big Anxiety - festival of arts+science+people}

Grounded in an understanding of subjectivity as an interactive process, The Big Anxiety project uses cultural environments and practice to examine the psychosocial processes whereby people engage with environmental factors that affect their own mental health or that of others and to envisage their re-design. As such its events constitute formative inquiry (which includes formal research) and knowledge creation through engagement, as opposed to what within a conventional 'medical model' is termed 'knowledge translation' (implying the dissemination of already existing knowledge for a lay audience of lesser expertise). The festival partners with the mental health sector on these terms, addressing key deficits perceived within that sectormost notably, the challenge that $65 \%$ of Australians with mental health issues don't seek helpproposing that without richer methods of engagement and communication, this $65 \%$ can't be reached. Its goal is to engage non-help seekers on new ground, creating settings or facilitating environments beyond the health sector that do not define users as help-seekers. It takes seriously the fact that non-help-seekers, by virtue of keeping out of the sector are not medicalised subjects; they may be distressed, but not subject to medical diagnoses or 'disorders' - and in this sense, not responsive to the affordances of service provision.

The festival project is motivated in part by the failure of mental health services to adequately address lived experience in its own terms and specifically by concern that complexity has been lost, due to the scientific reductionism of the dominant research paradigm and the concomitant focus on what is easily identifiable and measurable. This view is expressed in consumer-led calls to shift the attention from diagnosis and disorder towards the experiential (and in the mantra, 'it's not what's wrong with you, it's what happened to you'). Noel Hunter (2018) has also pointed to the loss of nuanced understanding incurred mental health with the waning of family-systems-oriented therapies developed in the 1960s and 70s. She notes that therapists in this tradition advanced understanding of the toxic and insidious effects of covert interpersonal dynamics (such as gaslighting, double-binds and scapegoating) locating psychological dysfunction within the family or social system (Hunter, 2018; Laing \& Esterson, 1964). If this work is occluded by excessive focus on bio-medical psychiatric intervention, it is nevertheless re-entering popular discourse in a period where, after decades of silence, institutional abuse is finally recognised and where there is a significant cultural shift (exemplified by \#MeToo) in terms of recognising behaviours of abuse. We suggest that arts-based psychosocial practice enables not only the expression of individual lived experience but its location within often hostile and oppressive institutional and social networks. By attuning to affordances we are able to explore covert interpersonal dynamics and the way in which these are embedded and habituated. Moreover, as the example of Parragirls shows, doing so via an arts-based investigation gives trauma survivors the means to do this themselves.

\section{Awkward Conversations}

The Awkward Conversations program creates opportunities for conversation in facilitating environments at public venues rather than in spaces that are coded as either art or health 
settings. Fundamentally, it aims to 'design away' the barriers to holding a conversation, attending to institutional positioning, affordances of place and to how a conversation that is awkward and anxiety provoking becomes possible and potentially transformative as a twoperson engagement beyond the realm of help-seeking. In 2017 it was launched in Customs House, a multipurpose site in the tourist hub of Circular Quay, owned by City of Sydney, housing restaurants and a library and attracting a continual flow of visitors. The program of Awkward Conversations was run from the front desk with volunteers acting as concierges taking visitors to one-to-one bookable conversations held throughout the building and forecourt.

Twelve different types of conversation were available, each lasting around 15-20 minutes. They were hosted by artists and others with life experiences of anxiety, neurodiversity and the mental health system. A conversation called The S-word, addressing suicidality ("for anyone who has ever thought about suicide - as well as those who haven't and feel they need to know more") was delivered in a corner of the public library by Alessandro, a host with lived experience. Autistic artist Dawn Joy Leong hosted conversations in purpose-built adjacent pods, designed to accommodate those not comfortable with close or face-to-face contact or the intrusive excesses of ordinary environmental stimulation. First Nations artist Amala Groom hosted a conversation about anxiety over a footbath using native medicinal plants. Other conversations were informally situated on comfortable chairs in the library foyer areas. Some made use of props (pens, paper, art materials), though the majority did not. Another conversation involved a walk around the Harbour with Debra Keenahan, an artist with achrondroplasia dwarfism.

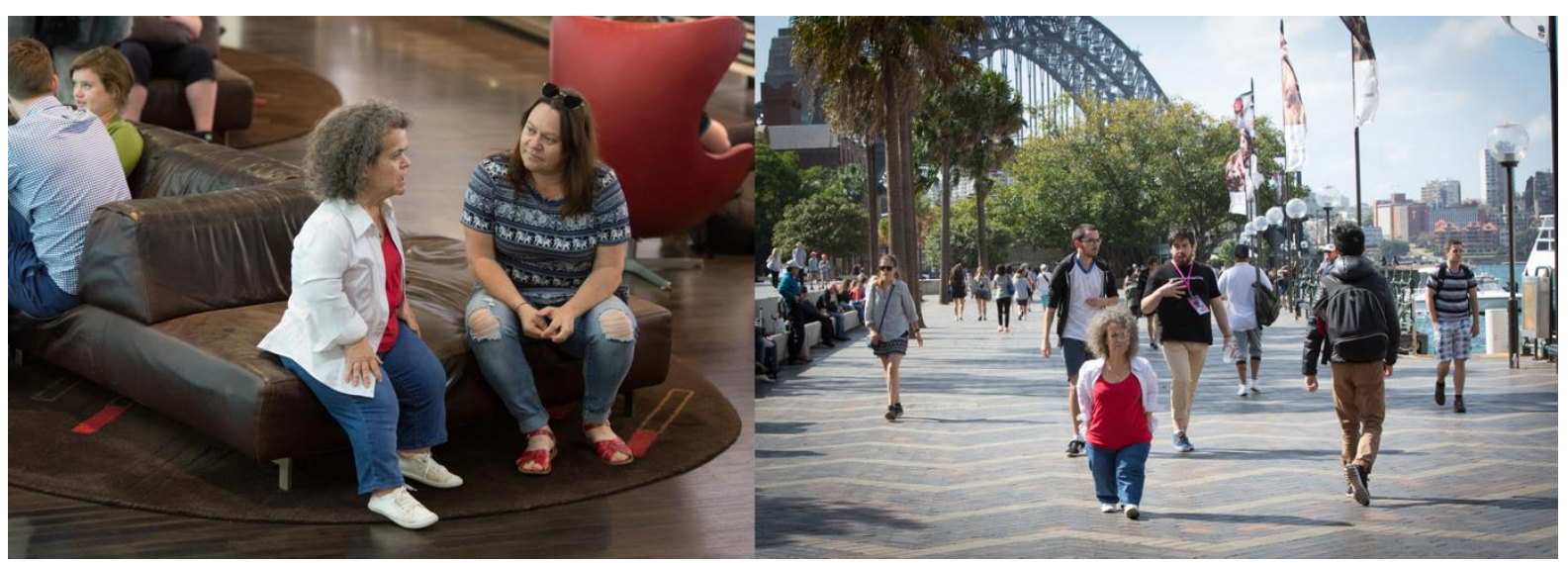

[Fig 1. left, Awkward Conversations in Customs House; Debra Keenahan's Awkward Conversation walk]

With the goal of engaging with the general public, including non-help-seekers who may require support - the aesthetic focus of the project lay in creating conditions where host and visitor could enter into a respectful dialogue in which the lived experience of both might be introduced. Thus, there was an offer to connect through experience insofar as it felt possible within the parameters of the conversation, but no expectation that participants should disclose personal information.

Hosts, drawing on their own lived experience, were invited to identify and arrange the spaces (with or without props) in which conversations occurred, and attention was paid to the comfort of transition via the role of the volunteer 'concierges' who also served as 'minders' at a discrete distance from the conversation. The design of the overall program and the individual conversations was thus shaped through attention to the affordances of the whole situation. 
The settings of the Awkward Conversations were created through purposefully crafting relational possibilities between the people and elements that are felt emotionally (attending to temperature, noise level, visibility, physical comfort, proximity and so forth) in each situation, with the goal of engendering an easily accessible, public but relatively secure and semi-private facilitating environment (Winnicott, 1965). This process is particularly apparent in Leong's conversation pods constructed out of translucent diaphanous material and conceived from the artist's autistic sensibility to support not only respite from sensory overload in the City but an experience of being 'together but separate' in dual pods.

If the practice-based approach to creating this space builds on Gibson's work, the operations of the environment owes more to the classic Winnicottian conception of a holding environment that is not just 'supportive' but able to secure or 'hold' the conditions in which a potential space can arise. Beyond the common-sense advantages of creating a conducive environment for conversation, the value of a holding environment constituted in an arts-based activation is to provide a temporary counterpoint to the relative lack of a secure holding in in society at large. The settings had to create conditions where people had permission (and literally the guidance of concierges) to walk-up and inquire about the things they had wanted to know but had always been afraid to ask - or to seek some initial support for unmet needs, even though it was made clear that this was not a counselling service.

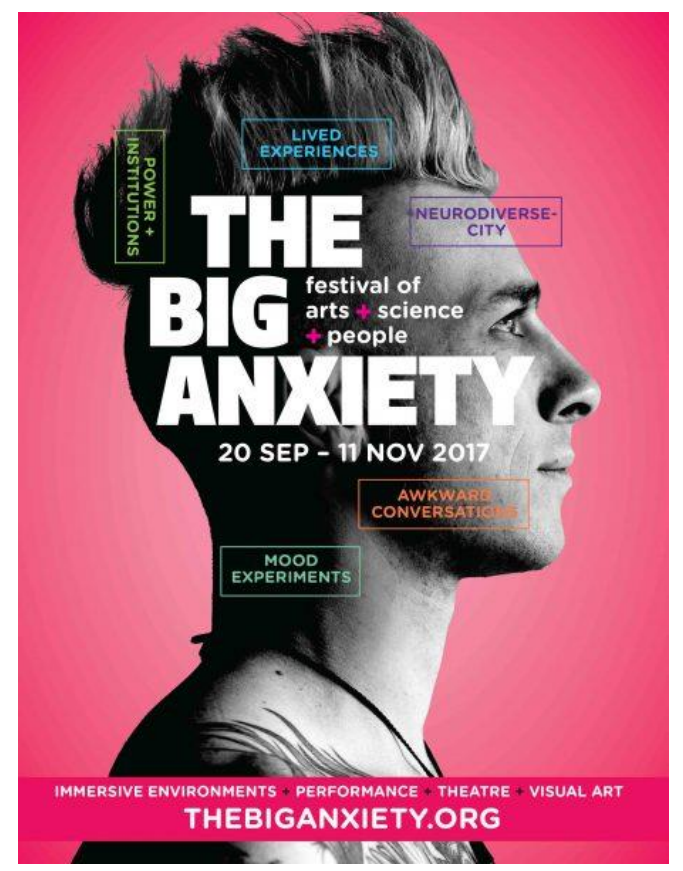

Capitalising on the potential for mental health conversation beyond the health sector, we also sought to preserve and play with a sense of the awkwardness attached to conversation about mental health. One of the hosts encapsulated this in reporting that he felt able to be his 'awkward self' in this setting, in contrast to working within a mental health setting where one is expected to be 'on message'. Participant feedback (via the festival survey) similarly reported: —Feels very positive to be able to talk about difficult
subject matter without having to filter or downplay"

\section{[Fig 2: The Big Anxiety poster]}

Rather than disavowing or overcoming awkwardness, we sought to use its transformative potential as something that under the right conditions can impel rather than obstruct a conversation.

Recoding the locus of conversation as an aesthetic space enables a process of feeling into and articulating each conversational partner's aesthetic presence (described by Bollas as 'idiom'; 1995). Each engagement in principle had to get to a point where it felt good as well as stimulating. This is not to distinguish the 'pleasure' of the arts from the functionality of therapy: "aesthetic moments are not always beautiful or wonderful...many are ugly and terrifying but nonetheless profoundly moving because of the existential memory tapped" (Bollas, 2011, p12). In this context a conversation that feels good is one in which in which apprehending the aesthetic presence of the other becomes possible because there is no compulsion to air-brush the awkwardness of the encounter. 
Accordingly, participants reported a range of emotion:

- "Anxious at first. Proud once had actually spoken to someone".

- "Overwhelmed but it felt like a necessary conversation".

They also ascribed positive sensation and emotion to the apprehension of the other:

- "Embraced. The Conversations were really comforting, and the artists were really giving."

- "Fulfilled and liberated by the ability to engage in meaningful conversations with strangers."

- "Not awkward at all. It was the first time I had the opportunity to speak to another person who had a similar express of mental illness to me."

In general, they reported feeling positive as a result of the encounter:

- "Really engaged and stimulated".

- "Open, confident, supported".

- "Energised Stimulated and engaged."

- "More connected to other people."

Artist Debra Keenahan's walking conversation incorporated a further dimension, co-opting social interactions (as affordances) into the conversation experience to promote a level of empathic unsettlement (LaCapra, 2001), whilst nevertheless ensuring the supportive holding environment of the one-to-one conversation. Keenahan's walk was designed to engage participants with the texture of her everyday experience. While many of the other hosts had lived with anxiety associated with neurodiversity or mental health issues, she identifies as disabled in respect of achondroplasia dwarfism and for her, anxiety comes from a hostile and disabling environment. It is a product of everyday social interaction, originating in the unease of others and the intrusiveness of their gaze. In Keenahan's words, "I will no longer be disabled when I can walk down a street in peace".

Her 15-minute walk brings into play the environment through which she and her companion move and the stares, comments, abuse and photography that her presence elicits. At one point in each conversation, Keenahan invites her companion to stand still and watch what happens behind her back while she proceeds alone for some 50 metres and then turns back toward them. Up to this point the two have been walking side by side but now the companion becomes a spectator in a live tableau as subtle and not so subtle intrusions unfold. Invariably, some passers-by turn to stare, others blatantly capture photographs (volunteers sometimes had to intervene when people assumed the right to photograph Debra after privacy was requested).

Keenahan (having psychology training) had studied the prevalence of an avoidant/resistant response to the 'novel stimulus' of an unfamiliar body. In her everyday experience, most people display reticence; at best unconfident in how to approach or meet her eye, at worst stigmatising and avoidant, with those lacking impulse control more overt in their response. Her expectation was that in facilitating an experience-near (Geertz, 1974) engagement, empathy could be engendered, not as a moral ideal but as a stance cultivated through perspective sharing and the act of 'being with'. Any detached expression of pity or moral indignation could be undercut by the face-to-face encounter. Thus, the experience promotes what La Capra calls 'empathic unsettlement' (LaCapra, 2001) but of a kind that arises from affective attunement (Stern, 2004; Gobodo-Madikizela, 2015, p1104).

Gobodo-Madikizela's Kleinian-informed approach to public victim-perpetrator encounters during the South African Truth \& Reconciliation Commission (Bennett 2005, GobodoMadikizela, 2015) is instructive here on the cultivation of empathy via face-to-face encounter. 
Public settings that carefully constitute facilitating environments may, argues GobodoMadikizela, serve as potential spaces facilitating the "emergence of unexpected moments that might create connections" (Gobodo-Madikizela, 2015, p.1099). In other words, the experiencenear encounter brokered within the facilitating environment can be the basis for imagining and feeling one's way into the other's perspective, experiencing and responding to their idiom and thus for humanising them and laying the basis for empathy.

Gobodo-Madikizela, herself a psychoanalytic psychologist, professes amazement at "the idea that the imagination is necessary even to recognize the existence, the human beingness, of the other" (Gobodo-Madikizela, 2015, p.1111) (amazement was of course, what was experienced in Keenahan's Awkward Conversation by stunned participants). Though 'extraordinary' this idea is borne out in the encounters that Gobodo-Madikizela brokered during and following the Truth and Reconciliation Commission, which lend support to Benjamin's conceptualization $(1990,1999,2004)$ of 'mutual recognition' as the core of intersubjectivity through which "the subject gradually becomes able to recognize the other person's subjectivity" (1990, p.33; Gobodo-Madikizela 2015). Benjamin (2004) describes "a relation in which each person experiences the other as a 'like subject,' another mind who can be 'felt with,' yet as a distinct and separate centre of feeling and perception" (p. 5). Gobodo-Madikizela suggests that: "The 'caring-for' element in empathy is the result of a deeper level of imagination and understanding of the other's experience. This deeper level of imagination takes 'feeling into' the mental state of the other to another level, and asks the question, What should I do about it?" (GobodoMadikizela, 2015, p.1112).

For Keenahan it was essential to reach this point of asking "What should I do about it?" In the event, Keenahan reported that three of her walking companions were shaken and moved to tears after witnessing the extent of this stigmatising behaviour in a live enactment. For her, this emotional reaction was unplanned but not entirely surprising - and within the holding space formulated for the conversation, such well-intentioned, affectionate responses could be effectively supported, processed and discussed. Saying "I'm so sorry!" is not for Keenahan a useful response, particularly since it calls upon her to then take care of the participant/bystander whose own emotion becomes the focus. The potential for being with and feeling into is thus carefully brokered by Keenahan as a shifting perspective onto the environment; at the end of the walk the companion is literally 'drawn in close' to arrive not at a place of full identification or appropriation but at a point of asking, "What are the options for action?".

From the intrusiveness, abuse and aggression of the public reactions to Debra we also have clues to the shame that may have been provoked in participants at their own unseemly or prurient curiosity, along with a desire to know more and also fear of causing harm. The maternal facilitating environment Winnicott had in mind was one in which the child may come to recognise and test the limits of their own phantasised destructiveness and here it is not only the holding but the resilience of the 'surviving' mother that enables her to be recognised as a 'like subject' to be 'felt with'. Similarly, if a relatively unconstrained exchange was to occur in an Awkward Conversation it required confidence in the survival of the host who could moderate without retaliating any aggressive inquisitiveness on the part of the conversational partner. Keenahan's expressed confidence in her own resilience comes primarily from a lifetime of learning from experience (Bion, 1970). Art practice here is guided by intuitive moves - which are in fact the mobilisation of past experiences and reflection applied to a unique situation (Muller 2012) and can be understood as particular forms of aesthetic intelligence in action. Here these are sustained by the aesthetics of the encounter and the 
affordances of the total situation with included the volunteers, concierges, framing and boundaries of the conversations and their material design.

\section{Parragirls Past, Present}

Parragirls is the name adopted by former residents of the Parramatta Girls Home [PGH], a state-controlled child welfare institution, adjacent to the convict-era Parramatta Female Factory in Western Sydney, Australia. In 2017, five Parragirls-Bonney Djuric, Lynne Paskovski, Gypsie Hayes, Jenny McNally, and Tony (Denise) Nicholas - collaborated with artists Lily Hibberd, Volker Kuchelmeister, and Alex Davies, on Parragirls Past, Present, an experimental 3D immersive film (23 mins long, screened in an immersive theatre or Virtual Reality headset). The film emerged from a longer-term community project with the women who had been committed to PGH as teenagers in the 1970s, having been deemed by the Children's Court to be neglected, uncontrollable or exposed to moral danger. The PGH regime was harshly punitive and girls were subjected to physical, emotional and sexual abuse. In 2017, the report of the Royal Commission into Institutional Responses to Child Sexual Abuse [RC] brought to public attention the scale of such abuse and a governmental apology followed in 2018. Produced at the time the women were testifying to the Commission, and with the buildings and grounds facing redevelopment, the film was conceived by the women to capture, document and to imaginatively re-inhabit the site on new terms.

The women's aim was not to evoke the horrors of the past (they are averse to sensationalising media coverage) but to take possession of the site and its representation in the present. Having lived for more than 40 years with the institutional denial of their abuse, freighted with the authority of official descriptions, making peace now entails wresting back control of the site's contested meaning. For this primary reason the creative team of the Parragirls and collaborating artists undertook terrestrial and aerial surveys to capture the whole complex. Rather than simply making a narrative film, the goal was to recreate the site and the experience of moving through it. No figures appear on screen, but the voices of the women guide us into and through the immersive experience, beginning with a recollection of the brutality of entering remand as we pass inside the walled compound:

When you go into any remand, you go for internal examinations. Now, you're virgins at this time... I remember being held down by staff members forcing internal ... you're screaming and the police are standing there and they're not doing a thing. And you were really scared ....after the brutal examination ... you are thinking what the hell else is going to happen to ya?'

Photorealistic imagery of a corridor and sandstone 'dungeon' area, of a segregation room and a laundry-each sparking different recollections-are interspersed with point-cloud representations which, while topographically accurate, create an aesthetic of fragmentation as objects and surface textures appear to break into pixels - delicate luminescent points of colour that "simultaneously generate the perception of authenticity and scientific accuracy while presenting a fragmented and broken world" (Kuchelmeister et al, 2018). The project, however, is not simply about what is remembered but how it is remembered, encountered, shared in a context where the truth of the women's experience was systematically denied and undermined, often leaving them with only the defences of dissociation and self-harm.

Psychoanalytic trauma theorists have drawn attention to the impossibility of witnessing massive psychic trauma during its occurrence. The force of the event precludes its registration, 
such that it is "a record that has yet to be made" (Laub, 1991). Moreover, within a totalitarian architecture, "the inherently incomprehensible and deceptive psychological structure of the event precludes its own witnessing" (Laub, 1995, p.65). As such, there were minimal but significant affordances enabling resistance in PGH; as the women's testimony to the Royal Commission affirms, "at Parramatta Girls Home, there was nowhere for any of the girls to go to talk" (RC Case Study 7, exhibit 17:29) but in the film the women describe escape attempts, the practice of scratching graffiti into the sandstone (which Bonney calls a "really remarkable act of defiance", given the punishment), the hiding of pins from the industrial sewing room under the skin; and the practice of harming their own bodies as a means to register survival:

My existence was my own damage. And that was my own bodily injuries. I chose that over the scratching because I was terrified of the consequence. And so, I marked myself and chose that way of seeing my own blood instead of seeing my name on a wall.

The film voiceover, created and spoken by the women, emerged through initial experiments in which they roamed the site in pairs, recording their conversations, and comparing memories and perceptions. Thus, the voiceover is less a narration for an imagined audience, than an emergent discussion. As with Awkward Conversations, the aesthetic technique was intended to promote a process of elaboration within a holding space-with the distinction that in this case, the facilitating environment had to be engendered within the walls of the Parramatta site. It is in this very profound sense, that Parragirls Past, Present differs from objective (or sensationalising) reports of the site's notorious past. The aim - and unique capacity - of the immersive film as an arts-based psychosocial inquiry was to locate the continuing effects of trauma in present day interactions. It is in this way that we come to understand the force of institutionalised discourse.

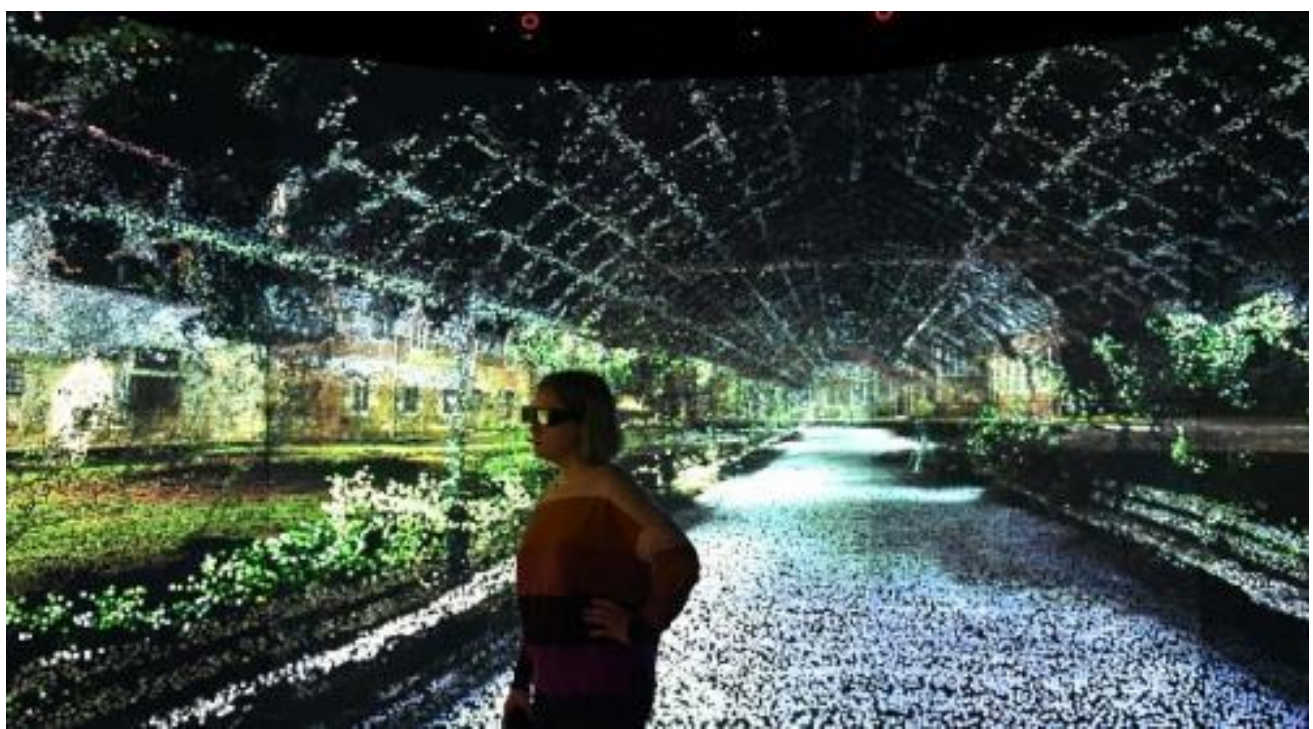

[Fig 3. Parragirls Past, Present 2017 [viewer in immersive 3D film]

Jenny McNally relates two key examples, each located at particular sites:

If we had muster, that's where they'd stand and that's why I was so offended when the FaCS [Family and Community Services] worker stood up there and started reciting the history of Parramatta Girls Home and getting it all wrong. And I just told her how I felt she was so flippant about the whole of Parramatta Girls Home. And how easy it fell; all this garbage fell out of her mouth that was so non-factual. And I just saw outrage.... 
Actually, it was very hard for me to bear. I just wanted to scream at her because she was lording over us. And the sad thing was she turned to me and said, "And who are you?" And I went regimented and I said my name. What I should have told her was, "Go f... go fuck yourself, love."

I said my name because she was standing on the step and I just transformed into an insignificant nothing and responded in the expectation that a superintendent would expect me to respond. And, oh, I was beside myself that that had happened. I was so angry that someone could turn me so quickly with, "And who are you?".

Such paralysis - often described in terms of 'triggering' - may be understood as replaying originary trauma in a process that Freud (1991) characterises as 'nachtraglichkeit' or 'afterwardsness' whereby later memories, struggles and the partial work of healing vanish and the trauma is reconstructed retroactively - as if time and memory had not elapsed. The paralysis returns, unbidden and unanticipated in an unresolved repetition not only of the experience but of the relations of powerlessness associated with the silencing - a 'deferred obedience' (Freud and Breuer ([1895] 2004) to an internalised and cruel authority.

In this retelling, the tables are turned on that authority. The audience is confronted not only with the painful legacy of abuse but with a sense of how authority is still assumed without question or insight within institutional settings in ways that re-enact coercive power relations. For the survivors themselves, the film - and film-making process-may be considered as a potential space that has the effect of expanding affordances for action. In this context the potential space enables the settled convention of authority to be re-figured and re-imagined so that agency now resides with the women themselves finding expression in an aesthetic object of their creation.

The 'paralysing' event recollected is not represented visually but is situated within the institutional architecture in a manner quite distinctive to immersive 3D film, which moves the viewer into and around the unpopulated grounds. Space in this immersive experiential medium is not backdrop but appears to open up and enclose; space, this time round, is made for the women's experience. At the point at which the violence of silencing was experienced 'internally' by Jenny, the film enables the registration of this experience: the space onscreen, depicting the vacated site of PGH, is momentarily stilled, so that it is envisaged as containing a felt response: a silent scream. It is a space where this can now be witnessed.

On a second occasion, described by Jenny, a visitor's response is even more insensitive:

We all went back to Bethel. Bonney was telling the history and one of the men turned around and said, "If all of these rapes happened, where are all the pregnancies? Where are all the babies?" And I was nearly sick. I was nearly sick. And Bonney answered so well. She just said, "They knew our cycle." And I went outside and I... I don't know if anyone's... I'm sure people have experienced this... I went outside and I was so explosive with that comment. I was so explosive with it. And I went outside and I did a silent scream. And I just stood there with my hands up thinking, "How dare anyone speak like that in front of us?

Towards the climax of film, this account of a devastating interaction is given its own expansive space; the camera moves away and up from the building mentioned, opening up 
a caesura at the spot where Jenny remembers herself standing, "hands up, thinking". The camera surveys the scene from above so that the women's voices now speak to and of the site below. As the camera continues to pan out encompassing the entire site, in an oblique aerial view, we hear on the sountrack the women's plea that government authorities must be answerable so that nothing like this will happen again. This calling to account reflects the dual purpose of testimony; Laub says of his work with Holocaust survivors that they "did not only need to survive to tell their stories; they also needed to tell their stories in order to survive" (Laub, 1995, p.63).

In the film Jenny talks about her dismay at being punished for nothing, describing her refusal to stay silent as a question of survival: "I have never hurt anyone. I just had a mouth on me, you know. I could have shut up, but I felt if I'd ever shut up, I wouldn't be who I am today". Jenny's published testimony (RC Case Study 7, exhibit 17) details a catastrophic failure of care, compounded at every level (family, school, church, welfare, government and judicial process). Throughout it, she describes how screaming was her only recourse, sometimes effective in the short term in warning off abusers, more often eliciting beatings. "I was screaming out and nobody would listen. Nobody heard. But I was so noisy, I don't understand how nobody heard" (RC 7.17.40).

The truth is that there was noise; many people - parents, schools, church, police, mental health professionals, authorities, courts, welfare workers, PGH staff - heard; nobody listened. Even a psychiatrist professes herself unable to understand why Jenny would 'muck up'. Yet, as Winnicott (1958) argued the apparent 'anti-social' tendency of children must be 'met' and understood as a reaction to environmental deprivation; that is to say, as a reaction to the lack of a facilitating or holding environment, notwithstanding "the roof over your head" for which Jenny was told by Child Welfare to be grateful (RC 7. 17.14). If the Royal Commission was able to bring to light the truth of institutional abuse, Parragirls Past, Present played a different reparative role.

As Bollas explains "the work of trauma is to sponsor symbolic repetition, not symbolic elaboration" (Bollas 1992, p.70). It is in the possibility of symbolic elaboration that we find the key to understanding the contribution of an artwork, especially one that brings memories of the past vividly into the present - not only as narrative re-enactment but also as 'lyric' creation, experienced immersively in the moment (Abbott 2007). For the Parragirls the filmand associated aesthetic process - offered a container for re-symbolisation, within which trauma could be transformed into psychic genera ("something that will link with and possibly elaborate the psychic material that is incubating into a new vision". (Bollas, 1992 p.79). Such symbolic elaboration is an essential counterpart of the political re-positioning of the self as 'survivor'. Without it survivalism is brittle, subject to set-backs, and can collapse into the into the dynamics of 'doer' and 'done to' that characterise the sado-masochistic relationship (Benjamin 2004). The conclusion of the Royal Commission and its wider reporting inevitably represented both welcome acknowledgement and a risk of disappointment and loss of control over the narrative, which the women sought to mitigate by generating their own project, grounded in their own recovery process. Most importantly, this was grounded in their aesthetic perception, felt experience and sensibility - factors to which no space was ever given.

The film offered a context in which the women's memories could in some sense be objectified in the materiality of the setting. The challenge was to work with the affordances of the environment, transforming them through the site exploration and film-making so that from a 
site of oppression PGH became an arena for the realisation of a hard-won resilience. In contrast to the discursive space of media exposure that is opened up in stories of the 'scandal' of Parramatta, the artistic process enabled the women to access the potential spaces of creative imagination which found expression in the narrative and imagery of the film - not a documentary but an aesthetic rendering of a structure of feeling (Williams, 1981) associated with the walkways and empty rooms of a place that now appeared less substantial through the shifting, breaking patterns of spectral point-cloud light

The point of making an artwork of the experience is neither testimony, nor representation. While the story is told in the voice over, something of the quality of feeling aroused for the Parragirls is made experientially available to the audience-but through the aesthetic containment of the film. In this context there is a reparative aspect (felt and told) to the replaying of fragments of traumatic memory, now transformed, re-symbolised and overlaid with a narrative of survival. What is at stake here is believability. As Jenny articulates in a subsequent video interview:

I think that's the most amazing thing... That I was believed. ... to have my first-born son, who was taken from me through Parramatta say, 'Mum, this is stunning and now I understand your story, I understand who you are'. It gave me back my reality... (McNally, 2017)

\section{Conclusion}

In this paper we have interwoven two forms of enquiry-creative practice-based research where enquiry into the aesthetics of lived experience is a driving force; and psychosocial evaluation of the engagements that take place in collaborative arts project. From a practice perspective we have highlighted the relational work of designing with affordances-felt opportunities for action that allow for an active empathic engagement that does not demand, nor allow a participant to easily co-opt, normalise or resolve the experience of another.

An awkward conversation is therefore not only awkward by virtue of its subject matter-its affordances enable active work with the discomfort that arises in the conversational dyad rather than seeking to ameliorate or 'art-wash'. The facilitating environment favours an 'optimal graduated awkwardness' (to paraphrase Winnicott) which can moderate inquisitiveness, embarrassment or diffidence by supporting both the self-awareness of the participant and the resilience of the 'surviving' host. The aim is to create the conditions of mutual recognition in which the reality of another is not so much explained as revealed in the encounter-a learning from experience (Bion, 1970) where it can be apprehended and thought about.

The knowledge acquired in the process does not substitute for critique of medicalised mental health systems or for therapeutic practice. Arts projects such as those described seek another route to shared understanding of mental distress which, following Alford's (1989), interpretation of Klein can be seen as a quest for empathic knowing which is rooted in Caritas, rather than Eros - where the desire for knowledge benefits the knower. Such a quest aims to achieve a compassionate knowing without impinging on or damaging the object: Love as Caritas 'lets its object be', rather than appropriating the other.

As interest grows in accounting for the mental health benefits of art there is a risk that measurable dimensions extraneous to lived aesthetic experience are foregrounded. A theorisation of the transformative potential of art therefore becomes ever more necessary. This 
can be derived - as we have indicated - from Bollas' account of aesthetic transformation, which expands Winnicott's conception of the 'environment-mother' to include its aesthetic aspect:

The mother's idiom of care and the infant's experience of this handling is one of the first, if not the earliest human aesthetic. [It] will predispose all future aesthetic experiences that place the person in subjective rapport with an object. (Bollas, 1987, p. 32-3)

For Bollas the expectation of being transformed by a process arises from the manner of the mother's tending through which she expresses her own distinctive idiom- "never cognitively apprehended but existentially known" (1987, p. 16), shaping an aesthetic intelligence that will be elaborated throughout life. Creative practice is likewise intuitively concerned with creating the conditions - the facilitating environment - through which the transformative aesthetic moment can be realised. This entails a delicate negotiation between control (the drive towards a strong aesthetic outcome) and the potential space that 'lets the object be', or 'become', whilst holding the arena of engagement.

The Parragirls project was coextensive with a public reckoning alongside which a different need arose - for a holding situation - no longer the forensic knowing and exposing of what had happened (a necessary step that Alford associates with Klein's paranoid schizoid anxiety and which is arguably accomplished in the detailed mapping of the site). Rather their impulse was a reparative re-inhabiting of the site, finding in its imaginative re-creation an alternative set of affordances. Rather than the repetition of incommunicable trauma, working with the potential spaces in the immersive film offered an opportunity for symbolic elaboration. To the extent that the film engenders the feeling of containment, it is the registration of a process by which the women determined to create a vehicle that could hold their experience. Thus, Parragirls Past, Present exemplifies aesthetic work in the limit case of massive trauma, itself marked by the systemic deprivation of a potential space that would enable a re-figuring of their relations to that trauma. It enables listening, hearing and opens the possibility of an empathic response.

In bringing the knowledge generated in practice-based enquiry into dialogue with psychoanalytically informed conceptions of the conditions and nature of aesthetic experience we have aimed to elaborate a concept of aesthetic intelligence at work through a distinctively psychosocial lens. We have shown how such an approach can in practical ways enable the fundamental components of an empathic response, and how and why such a response must be actively enabled where inhospitable conditions exacerbate anxiety and trauma. Through greater aesthetic attunement we can provide options for action.

\section{References}

Abbott, A. (2007) Against narrative: A preface to lyrical sociology, Sociological Theory, 25(1): 67-99

Alford, F. (1989) Melanie Klein and critical social theory: An account of politics, art and reason based on her psychoanalytic theory New Haven and London Yale University Press

Bartlett, V. and Muller, L. (2017), Curating/containing: Exhibiting digital art about mental health. In: J. Arango, A. Bubarno, F Londoño and G. M. Mejía (eds), ISEA2017 BIO- 
CREATION AND PEACE, Manizales, Columbia, International Symposium on Electronic Arts.

Bollas, C. (1987) The shadow of the object: Psychoanalysis of the unthought known, London: Free Association Books

Bollas, C. (1992) Being a character: Psychoanalysis of self-experience, New York: Hill \& Wang

Bollas, C. (1993) Being a character: Psychoanalysis and self experience, London Routledge

Bollas, C. (1995) Cracking up: The work of unconscious experience, London: Routledge

Bollas, C. (2011) 'Psychic Genera', The Christopher Bollas reader, London, Routledge

Benjamin, J. (1990) 'An outline of intersubjectivity: The development of recognition', Psychoanalytic Psychology, 7(Suppl): 33-46.

Benjamin, J. (1999) 'Recognition and destruction: An outline of intersubjectivity', in S. A. Mitchell andL. Aron (eds), Relational Psychoanalysis: The Emergence of a Tradition, Hillsdale, NJ: Analytic Press. pp. 181-200.

Benjamin, J. (2004) 'Beyond doer and done to: Recognition and the intersubjective third', Psychoanalytic Quarterly, 73: 5-46.

Bennett, J. (2005) Empathic vision: affect, trauma, and contemporary art, Stanford, California: Stanford University Press.

Bennett, J. (2012) Practical aesthetics. Events, affect and art after 9/11, London: I.B. Tauris \& Co.

Bennett, J. and Froggett, L. (2019) 'Aesthetic intelligence', in J. Bennett and M. Zournazi (eds), Thinking in the world reader, London Bloomsbury

Bennett, J., Froggett, L., Kenning, G., Manley, J., Muller, L. (2019) 'Memory Loss and Scenic Experience: An Arts Based Investigation', Forum: Qualitative Social Research, 20(1).

Bion, W. (1970) Attention and interpretation, London: Karnac.

Freud, S. ([1919] 2003) The uncanny, London: Penguin Books

Freud, S, (1991) Case Histories II, London: Penguin Books

Freud, S and Breuer, J ([1895] 2004) Studies in Hysteria, London Penguin Classics

Gendlin, E. (2009) 'We can think with the implicit, as well as with fully-formed concepts', in K. Leidlmair (ed), After Cognitivism: A Reassessment of Cognitive Science and Philosophy, New York: Springer-Verlag New York Inc 
Gibson, J. (1979) The ecological approach to visual perception, Boston: Houghton Mifflin

Gobodo-Madikizela, P. (2015) 'Psychological repair: The intersubjective dialogue of remorse and rorgiveness in the aftermath of gross human rights violations', Journal of the American Psychoanalytic Association, 63(6): 1085-123.

Hunter, N. (2018) Trauma Outside the Box: How the 'Trauma-Informed' Trend Falls Short, https://www.madinamerica.com/2018/11/trauma-informed-trend-falls-short/.

Kuchelmeister, V., Hibberd, L. and Davies, A. (2018), Affect and place representation in immersive media: The Parragirls Past, Present project. In: J.P. Bowen, J. Weinel, G. Diprose andN. Lambert (eds), Electronic visualisation and the arts 2018, Electronic visualisation and the arts. pp. 71-78.

Laing, R. and Esterson, A. (1964) Sanity, madness and the family, London: Tavistock Publications.

Langer, S. (1942) Philosophy in a new key: A study in the symbolism of reason, rite, and art, New York: NAL Mentor.

Langer, S. (1953) Feeling and form: a theory of art, New York: Scribner's.

Laub, D. (1991) 'No one bears witness to the witness' in S. Felman and D,. Laub (eds) Testimony: Crises of witnessing in literature, psychoanalysis and history, New York: Routledge

Laub, D. (1995) 'Truth and testimony: The process and the struggle' in C. Caruth (ed) Trauma: Explorations in memory, Baltimore: Johns Hopkins

LaCapra, D. (2001) Writing history, writing trauma, Baltimore, Md: Johns Hopkins University Press.

McNally, J (2017) Jenny McNally Interview, Parramatta https://www.youtube.com/watch?v=4hFS8-Fq-c8

Muller, L. (2012) 'Learning from experience: a reflective curatorial practice', in Candy. L and Edmonds. E (eds), Interacting: art, research and the creative practitioner, Oxfordshire, Libri Publishing. pp. 94 - 106.

Muller, L., Froggett, L. and Bennett, J. (2018) 'Emergent knowledge in the third space of artscience', Leonardo: 1-11.

Royal commission into institutional responses to child sexual abuse: Case study 7 https://www.childabuseroyalcommission.gov.au/exhibits-case-study-7

Stern, D. (1985) The interpersonal world of the infant: A view from psychoanalysis and developmental psychology, New York: Basic Books.

Stern, D. (2004) The present moment in psychotherapy and everyday life, New York: Norton 
Williams, Raymond. (1981) The sociology of culture. Chicago: University of Chicago Press.

Winnicott, D. (1958) 'The antisocial tendency', in Collected papers: Through paediatrics to psycho-analysis pp.306-315. London: Tavistock

Winnicott, D. ([1965] 1990) The maturational processes and the facilitating environment, London: Karnac.

Winnicott, D. (1971) Playing and reality, London: Tavistock.

Wright, K. (2009) Mirroring and attunement: self-realization in psychoanalysis and art, Routledge: Hove. 